\title{
CRIANÇAS E JOVENS, ATORES SOCIAIS NA ESCOLA. COMO OS COMPREENDER?*
}

\author{
PATRICK RAYOU ${ }^{* *}$
}

\begin{abstract}
RESUMO: Este texto apresenta uma reflexão sobre o processo metodológico que iniciei por ocasião de pesquisas que venho fazendo há 12 anos sobre a socialização das crianças e dos jovens de níveis diversos de escolarização. A preocupação de me liberar do "adultocentrismo", que muitas vezes impede de aceder às categorias específicas da experiência social infantil, levou-me a utilizar instrumentos de pesquisa que escolhi múltiplos e adaptados a atores socais em toda a extensão da palavra. Crianças e jovens não se comportam como adultos acabados, são, porém, tanto quanto estes, desejosos de analisar e de redefinir no seu próprio interesse as coerçôes situacionais sobre eles exercidas individualmente ou coletivamente. Para entender as tribulações que assim enfrentam como o sentido que eles lhes dão, utilizei, de modo geral, entrevistas inspiradas em métodos etnográficos, mas criei também cenários a partir dos quais crianças podem exprimir perfeitamente conceitos, já bem elaborados, sobre a justiça e a vida pública. O estudo de incidentes-chave ou de "negócios" levando-os a enfrentar atores adultos permitiu-me igualmente apresentar algumas propostas sobre as diversas maneiras que eles têm de viver juntos em diferentes momentos da escolaridade. Enfim a importância dada ao objeto do trabalho escolar, como a redação de textos "longos", permitiu-me abordar a relação aos "saberes" de um ponto de vista que a narração da experiência, somente, oculta de modo geral. Em todas essas pesquisas, esforcei-me igualmente a não opô-las; tentei, de preferência, conciliar pontos de vista qualitativos com tratamentos quantitativos na esperança de ter acesso simultaneamente ao significativo e ao representativo.
\end{abstract}

Palavras-chave: Socialização. Crianças. Jovens. Escola. Metodologia.

\footnotetext{
* Tradução de Maria Fonseca, com revisão técnica de Ivany Pino.

** Professor do Instituto Universitário de Formação dos Mestres de Créteil (França), Equipe Escol - Paris 8. E-mail: rayou@noos.fr
} 
Children AND young PEOPLE AS SOCIAL ACTORS IN SCHOOL. HOW TO UNDERSTAND THEM?

ABSTRACT: This article presents a reflexive analysis of the methods of investigation that I have used over twelve years of research on children and youth socialisation at different school levels. The desire to free myself from an "adult-centred" position that prevents researchers to reach the specific categories of children's social experience has led me to develop multiple research tools adapted to these social actors. Children do not behave, it is true, as accomplished adults, but they wish, as them, to analyse and redefine at their advantage the situational constraints that they meet individually or collectively. To understand the trials they are confronted to and the meaning they give to them I have used ethnographic interviews, but I have also conceived scripts from which children can perfectly express well-developed conceptions of justice and politics. The analysis of key incidents or "affairs" that confront children to adults has also allowed me to put forward some propositions concerning their group sociability at different points in their school careers. Finally, the examination of some dimensions of schoolwork such as "long" written texts has led me to analyse a relationship to school "knowledge" that life stories usually neglect. In all these research studies, I have tried to combine qualitative and quantitative approaches rather than opposing them in the hope of both gaining insight and being able to generalise.

Key words: Socialisation. Children. Youth. School. Methodology.

\section{Das sociedades e dos seres em construção}

O

fato de levar a sério a temática de uma socialização infantil é hoje facilitado pelo sucesso das sociologias (Corcuff, 1995) que apreendem as realidades sociais como construçôes históricas e cotidianas dos atores individuais e coletivos. Se for verdade que, sobre o pano de fundo de "declínio da instituição" (Dubet, 2002), o indivíduo aparece como outra coisa que um resíduo tendo escapado à força integradora do social, o lugar da infância encontra-se também muito fortemente redefinido. Pois, nas sociedades que não mais coincidem com os contornos geográficos das nações, a criança não pode mais ser considerada um ser caracterizado por pulsões pré-sociais, até mesmo anti-sociais e que ter-se-ia de civilizar rapidamente (Durkheim, 1966). Pode-se considerar que as crianças e os jovens, particularmente na escola, onde passam de 
agora em diante, cada vez mais, mais tempo, uma grande parte da vida, são confrontados, como os adultos, com numerosas provas (Boltanski \& Thévenot, 1987) que se tornam as verdadeiras matrizes da sua socialização. Crianças e jovens devem, como os adultos, submeter-se às provas de realidade, únicas suscetíveis, num mundo de múltiplos princípios de legitimação, de liberar "valores" orientados para a justiça e sendo objeto de um acordo. Pareceu-me que a noção de prova permitiria pensar a continuidade, mas também a ruptura, entre os modos de sociabilidade infantis e adultos. Faltava experimentar diferentes "bricolagens metodológicas" para tentar mostrá-lo.

\section{Entrevistas e categorias da experiência}

Minhas pesquisas sempre utilizaram metodologias qualitativas, mesmo se tentei utilizar também enquetes por questionários a elas articuladas. Houve ao assim fazer, evidentemente, uma espécie de facilidade ligada à minha formação literária, assim como ao contexto no qual as comecei e no qual as enquetes por entrevistas se desenvolviam numa crescente desculpabilização face às formas até então dominantes da abordagem estatística. Mas a emergência dessas metodologias e o fato de eu a elas recorrer não podem ser, verossimilmente, reduzidas a apenas isso, pois elas parecem uma passagem quase obrigatória para quem quer estudar a fundo o que poderia haver de específico na experiência social das crianças e dos jovens e que não encontra os instrumentos apropriados nas categorias fabricadas para outros que eles próprios. Uma metodologia de inspiração etnográfica parecia se impor, sobretudo se fosse aparentada à do tipo "combinatório" (Baszanger \& Dodier, 1997), particularmente apta na exploração de um universo de experiências determinadas. As vias clássicas da etnografia integrativa (que constrói coletivos de pertencimento para os indivíduos) e da etnologia narrativa (que conta na primeira pessoa acontecimentos da enquete) não podiam convir ao meu objeto. No primeiro caso, com efeito, confinam as crianças e os jovens nas instituiçóes escolares ou num entre-si hermético; no segundo, fornecem vivências que, por originais que sejam, não podem, sozinhas, mostrar o que têm de específico.

O interessante de uma etnografia do tipo combinatório é identificar, segundo o que dizem os entrevistados, as diversas formas de ação nas quais as pessoas podem se engajar, assim como suas possíveis combinações. A totalidade da referência levada em consideração não é mais, nesse 
caso, dada a priori, mas consiste em recursos disponíveis para agir, levando-se em conta as coerções situacionais. Ora, precisamente, levar em conta as experiências particulares vividas pelas crianças e pelos jovens permite ao pesquisador lutar contra seu adultocentrismo "espontâneo", porque este último vai interessar-se ao mesmo tempo pelas coerções vividas e pela possibilidade de redefinição das situações que as provocaram. Nessa abordagem da questão, a alteridade da infância não provém mais nem do seu pertencimento a entidades particulares nem do seu não-pertencimento a qualquer entidade social, mas da diferença de um saber próprio adquirido no seio de experiências específicas. Torna-se então possível visitar estas últimas como um conjunto de situações que conhecemos ou que poderíamos ter conhecido sem nos confinar nunca na oposição binária e esterilizante do mesmo e do outro absolutos.

A enquete por entrevista faz aparecer categorias por intermédio das quais os atores contribuem à construção do seu mundo social. Tais categorias ajudam a reconstituir um espectro das respostas possíveis diante das situaçóes vividas, certos interlocutores abrindo portas, mais rapidamente que outros, a posições mais facilmente identificáveis porque mais arquetípicas. Tal estudante de liceu ${ }^{1}$ pode, por exemplo, dissociar totalmente a filosofia ensinada na sala de aula, e pela qual, talvez, ele se interesse, da filosofia do exercício escolar chamado dissertação, ${ }^{2}$ que, segundo ele, traz quando muito "conhecimentos". A primeira permite trocar idéias com os colegas, ao passo que a segunda só faz submeter a julgamentos escolares mais severos e aleatórios que os de outras matéri$a^{3}{ }^{3}$ e cuja temível particularidade é de avaliar as pessoas, pelo menos, tanto quanto os conhecimentos delas. Outro, contrariamente, vê na dissertação o prolongamento da sua experiência de diálogo epistolar, acha que escrever faz evoluir seu pensamento e vê nesse exercício a prova da exatidão do ponto de vista de "Hegel, que dizia que o pensamento chega quando se tem a palavra e é verdade que isso dá certo". Essas duas posturas extremas do "exit" (Hirchman, 1972), uma por retraimento de si, outra pelo empenho empregado na preparação desse tipo de dever, deixam ver claramente, na sucessão das atitudes que as une, os tipos de problemas levantados por esse exercício entre os estudantes do liceu de massa, assim como as estratégias individuais e coletivas utilizadas para resolvê-los.

Assim concebidas e realizadas, as enquetes com as crianças e os jovens podem, do mesmo modo que as que podem ser feitas com as pesso- 
as idosas, dar acesso a uma generalidade dos comportamentos os quais fazem sobressair as grandes lógicas e os dispositivos que os sustêm. Detectar estas generalidades não é descobrir um mundo à parte, pois se pode mesmo, fazendo variar mentalmente as condições das provas exigidas, ajustar esses esquemas da ação social aos dos adultos. Tal método parece então bastante conciliável com a posição antropológica segundo a qual a diferença entre crianças e adultos, do ponto de vista sociológico, é apenas de alguns graus e que, particularmente, a situação dos grandes adolescentes de hoje é, sob vários aspectos, uma lente de aumento da situação em que vivem também os idosos nas sociedades modernas menos "instituintes" que no passado.

Desde as primeiras enquetes, tive de renunciar a interrogar os estudantes de liceu como o faz um professor, mesmo tendo "boas relações" com eles. Fazê-lo enquanto tal seria me condenar, com efeito, a ficar surdo diante do que tinham vontade de dizer sobre o tema da amizade, que ocupava a quase totalidade do que diziam. Pois as perguntas diretas sobre os projetos perseguidos ou o interesse pelos cursos acabavam na maioria das vezes em respostas convencionais, seja no sentido da adesão seja no da oposição. Levar a sério o "fio" da amizade, a "philia", permitiu, em compensação, percorrer o mundo do liceu através das categorias que são especificamente as dos seus alunos: há uma coerência a ser mais ou menos amigo dos saberes, dos professores e dos seus colegas de classe, uma lógica muito consistente na maneira de afastar ou de reter elementos na construção de um mundo legítimo (Rayou, 1998). A descoberta ulterior de pesquisas sociológicas apresentando os métodos de investigação da "teoria enraizada" (Strauss, 1992), elaborando em permanência seus parâmetros de análise em função da capacidade desses parâmetros de prestar contas do material empírico, me confirmou a necessidade de renunciar às hipóteses iniciais quando as questôes supostas para verificá-las encontram nos entrevistados apenas um fraco eco. A existência de um "outro liceu", que os estudantes constroem no estabelecimento oficial, só pode aparecer se aceita a hipótese, a priori incôngrua, de uma maneira de viver na instituição que respeita suas regras por razões diferentes das que presidem à sua existência formal.

O desejo de enraizar a "teoria" da "philia", para não fazer dela a simples ilustração de uma tese filosófica, levou-me a mudar, durante a pesquisa, as modalidades das entrevistas. Tendo observado que os alunos "produziam" muito mais informaçóes quando se juntavam dois ou três, 
deixei-os formar pequenos grupos que aceitavam ser gravados. Metodologia e problemática ajudavam-se mutuamente, pois me dava conta de que os alunos ${ }^{4}$ se abriam mais desde que confortados pelo número e pela relação eletiva que os unia, e que pensavam não ter muito o que temer de alguém, o qual, no entanto, pelo seu estatuto, era próximo da instituição sobre a qual se lhes pedia para falarem. Uma tal relação de confiança era tanto mais necessária que era preciso poder encontrar os mesmos estudantes enquanto freqüentavam o liceu para verificar se as categorias com as quais construíam sua experiência em Segunda eram as mesmas até a Terminal ou se evoluíam em razão da percepção das provas a afrontar.

A metodologia da "teoria enraizada" parece particularmente oportuna para assegurar a passagem entre os diferentes mundos sociais, pois que a comparação contínua que ela realiza (Strauss, 1992) autoriza tanto o acesso às "teorias locais", que colocam somente em forma a experiência dos atores a quem diz respeito, quanto as "teorias formais", que atingem as condições estruturais do social. É sem dúvida possível ver nos fenômenos aparentemente bastante disparatados, como o modo que têm os alunos do primário de pôr sob a tutela de um "coro" suas relações amicais (Rayou, 1999a), as dificuldades dos estudantes de liceu a intervirem na vida escolar do seu estabelecimento ou a se investir no espaço de discussão constituído pela dissertação, aspectos de uma mesma tensão entre a esfera privada de uma vida pessoal e a esfera pública de uma vida de alunos. A análise de cada uma dessas tensôes pode oferecer, em razão do direito que se reconhecem aos alunos a fazer aceitar suas particularidades num espaço escolar que a filosofia republicana não previu para tanto, uma chave para a compreensão das evoluções contemporâneas do sistema de educação segundo seus diferentes graus.

Com a pesquisa sobre os alunos da escola primária tive de me confrontar com dificuldades metodológicas específicas. O primeiro tipo de problema com o qual me deparei foi o de tomar uma posição, de princípio, diante do estatuto da palavra das crianças: que confiança se pode ter no modo de como falam da sua experiência? Meu ponto de vista era o de levar a sério o que diziam por pouco que fossem postos em situação de expor suas competências. Reencontrava assim as preocupações metodológicas de sociólogos, que, como Andrew Pollard (1984, 1987), pensam que a dúvida que se tem com relação à confiabilidade das crianças deve, na realidade, concernir ao conjunto das sociologias interpretativas e pode 
aplicar-se tanto às palavras dos adultos quanto às das crianças. Desde então, a primeira dificuldade levava a uma segunda: como criar as condições de enquete suscetíveis de liberar uma palavra infantil ao mesmo tempo audível por um adulto e em relação com a experiência real dos alunos? $\mathrm{O}$ risco, imediatamente pressentido, era o de fazer perguntas que suscitassem nas crianças respostas vindas diretamente do discurso dos pais a respeito da atualidade do momento. Inteiramente capazes de psitacismo sobre as oposições entre direita e esquerda ou sobre o escândalo de tal ou tal fato da atualidade internacional, as crianças mostravam-se, em compensação, muito mais analíticas desde que tinham, por exemplo, de explicar uma injustiça sofrida ou testemunhada. O método dos cenários, utilizado por Piaget (1932), apareceu-me então como uma solução possível, pois tal método propunha às crianças situações probatórias que faziam surgir os princípios de julgamento e de ação em curso na experiência delas. A lógica binária na expressão desses princípios (eu lhes perguntava, por exemplo, o que era mais importante: ser a preferida da professora ou a da faxineira da escola) parecia lhes convir e o conteúdo mesmo dos casos sobre os quais eram convidadas a se pronunciar tinha sido determinado com base no material coletado durante um ano de entrevistas com crianças de diferentes escolas. A quase certeza de que o universo dos casos de justiça sobre os quais elas deviam estatuir estava bem, tanto no fundo quanto na forma, próximo do delas deixava esperar que, como para os adultos, as justificaçôes dos seus pontos de vista eram portadoras de generalidades a partir das quais se estrutura a experiência social (Demazière \& Dubar, 1997).

A entrevista sobre os estudantes (Crefi et al., 1999) permitiu-me concretizar metodologicamente a idéia de co-construção das situações. O recurso possível a numerosas entrevistas procedentes de estudantes e de professores-pesquisadores de três universidades autorizava, com efeito, a busca de categorias próprias a cada um desses dois mundos, mas também das que podiam ser comuns aos dois. Foi assim, por exemplo, que pude isolar a categoria de "espera", suscetível de exprimir ao mesmo tempo não só a necessidade de se dar um momento de reflexão sobre si mesmo, de maturação, mas também a utilização de eufemismo para exprimir a falta de apetite pelo saber universitário. À análise transversal das entrevistas relativas a cada uma das duas categorias de atores referidos se articulou uma outra leitura transversal, destinada a detectar o que provocava tensão ou colocava de acordo as lógicas de cada grupo de co-cons- 
trutores: os estudantes, quer sejam crianças, jovens ou futuros profissionais, parecem então participar da definição de um mundo de preferência apaziguado com os adultos, sucessivamente, pais, professores e pesquisadores.

Essas poucas "bricolagens" deveriam evidentemente ser questionadas a fundo, refeitas na perspectiva de novas pesquisas. Elas objetivavam abarcar da melhor maneira possível os contornos da experiência específica desses atores. Sem dúvida alguma essas "bricolagens" respondem melhor à dimensão temporal dessa experiência que à sua dimensão espacial. Pois, sem dúvida, os atores entrevistados contam mais facilmente as sucessões, as causalidades que descrevem uma mobilização do espaço sobre a qual, regra geral, eles pouco refletem e que praticam com o torpor da consciência que prevalece no momento da utilização dos dispositivos cotidianos. Nessa altura do assunto, o recurso a formas de observação definidas a partir do projeto de uma clara evidência das competências políticas impor-se-ia.

\section{Chaves para as cidades infantis}

As metodologias qualitativas parecem ser as mais adequadas para se tentar penetrar nas construçōes infantis relativas à vida política e à ação no espaço público em geral. As categorias socialmente consagradas podem ser, com efeito, profundamente alheias às preocupações das crianças e dos jovens. Nas pesquisas ou enquetes correntes sobre estes últimos aparecem, assim como fatos polêmicos que não podem encontrar explicação nos termos geralmente pertinentes para analisar os comportamentos dos adultos. Dessa forma é que os "barômetros" políticos, que, nos anos de 1990, mostravam nas imagens do abade Pierre ${ }^{5}$ e de Nelson Mandela dois personagens regularmente plebiscitados pelos estudantes de liceu, indicavam fenômenos incompreensíveis para quem não procurava ver, atrás da filosofia política precisa de cada um deles, o que podiam representar aos olhos de adolescentes interessados pela defesa dos "pequenos", qualquer que fosse o lugar do mundo onde estes últimos se encontrassem. Fora das adesões partidárias, essas duas figuras emblemáticas lhes pareciam criar uma reciprocidade humanitária real que deploravam nem sempre ver existir para eles próprios na escola e que desejavam ver reinar no mundo inteiro. Mas as enquetes correm o risco de efetuar más traduçôes das categorias dos atores. Assim é que, no meu próprio trabalho de pesquisa, por exemplo, fui leva- 
do rapidamente a renunciar a utilizar as noções de justiça discutidas pelos adultos no momento da guerra em Ruanda. Os alunos interrogados viam, com efeito, os conflitos entre Hutus e Tutsis em termos de "grandes" e "pequenos", características físicas que, para os analistas políticos, não eram suficientes, é claro, para explicar a guerra civil. Era necessário, pois, achar outros meios que pudessem evitar a utilização de noções elementares marcadas pelo adultocentrismo.

O aparecimento de acontecimentos-chave revelou-se desse ponto de vista precioso. Essa noção, tomada emprestada à etnografia (Wilcox, 1982), permite com efeito mostrar claramente as lógicas comuns que servem de base ao social e que passam despercebidas enquanto não são contestadas por um acontecimento que perturba a organização habitual dos seres e das coisas. $\mathrm{O}$ incidente sobrevindo durante a enquete com os estudantes de liceu ${ }^{6}$ (Rayou, 2000) foi bastante importante para fazer compreender como essa categoria de estudantes se afirma no interior do estabelecimento freqüentado. Quando tomam o risco de contar numa publicação as piadas que circulam entre eles sobre adultos do estabelecimento, colocam estes últimos numa situação que os obriga praticamente a reagir. Tal acontecimento, de um certo modo, deixou claro as diferenças e as incompatibilidades fundamentais das lógicas juvenil e adulta: os estudantes não sabem necessariamente que quase ultrapassam o limite que separa a brincadeira da difamação, os professores e os administradores nem sempre compreendem que responder pela greve ao que julgam às vezes como uma provocação política não será compreendido pelos jovens. Esse episódio, que abalou profundamente o estabelecimento, revela pois, indiretamente, que as condições de paz relevam de uma arte da discrição por parte dos alunos tanto quanto de uma capacidade de fechar os olhos desenvolvida pelos professores. Um outro incidente serviu para revelar a fragilidade da construção dos estudantes de liceu, dessa vez no que diz respeito ao espaço público fora do estabelecimento. Trata-se do "negócio dos capacetes", sobrevindo num liceu muito menos pacífico, que parece mostrar que, quando os alunos "pobres" da classe roubam aos mais "ricos" objetos de evidente valor comercial (no caso presente, capacetes de moto), eles incitam ao conflito entre colegas, obrigando assim o pesquisador a levar em conta categorias externas àquelas sobre as quais, de modo geral, uma comunidade funda sua igualdade.

Os acontecimentos-chave são tanto mais instrutivos que tomam a "forma de negócio importante" (Boltanski, 1990). Eles se prestam, com 
efeito, à exposição das diferentes lógicas nas quais o acontecimento foi construído, visto que cada ator ou grupo de atores foi levado a cair na generalidade para explicar a justeza da sua posição num conflito em que era impossível não tomar posição. $\mathrm{Na}$ questão do jornal dos estudantes evocada anteriormente, apareceram grandes diferenças na maneira como jovens e adultos caracterizam e dominam os modos de intervenção na cena pública, revelando assim comportamentos pessoais. Mas aí se pode ver também rupturas no seio de cada um dos grupos de protagonistas. Os professores invocaram lógicas pedagógicas, administrativas ou políticas que nem sempre eram coerentes, os alunos revelaram insegurança na qualificação do próprio ato. A preocupação de autenticidade que compartilham entre colegas se torna, com efeito, um delito quando afirmada com vigor numa intervenção pública que dá ao discurso deles um impacto bem maior que o das simples palavras que empregam de ordinário na estrita interação entre colegas. Essa brincadeira que acabou mal lembra a que evocou Milan Kundera (1985), na qual um banal "viva Trotski" valeu, ao autor da carta que acabava de escrever, graves aborrecimentos. A brincadeira tornou-se uma questão política da maior importância porque não tinha solução no sistema social da época; ela revela, mais do que vale por si mesma, a lógica de uma construção política. Do mesmo modo, o estudo da agitação gerada por essa publicação inábil leva a melhor compreender a natureza e os limites da ação dos estudantes de liceu no espaço público. E isso tanto mais que o método "de comparação contínua" permite extrair esse episódio da sua singularidade, demonstrando em outros episódios, em curso, como o do deslize de uma festa organizada pelos alunos no liceu onde mostraram sua incapacidade a refrear um "Père Cent" que havia começado na bonomia e que acabou num tumulto urbano, a junção muito difícil do mundo deles ao espaço cívico.

Acontecimentos-chave e fatos parecem ser objetos interessantes para uma resposta à dupla objeção geralmente feita aos métodos qualitativos utilizados nas enquetes sobre as crianças. A questão de ter confiança no que dizem parece ser resolvida em grande parte quando se interessa a fatos que colocam em interação vários atores que podem, certamente, propor versôes concorrentes dos acontecimentos, mas que também sabem que essas versões serão confrontadas com as de outros protagonistas. Do mesmo modo a questão da generalidade das análises, que o discurso de alguns entrevistados a respeito de interações limitadas autoriza, acha-se também, em parte, revogada, se se pode, por confronto de situaçóes di- 
ferentes sobre temas comuns, mostrar homologias assim como a aparição de uma "saturação" à qual o fato de se levar em conta outros casos não ajuntaria fundamentalmente nada. Assim é que o relato, na universidade, do "escândalo" que constituía, para certos estudantes, o fato de terem de recomeçar um exame o qual um deles teria fraudado, permite estabelecer uma ponte entre a justiça escolar dos alunos de liceu e a dos estudantes universitários. A convicção de que uma reparação da injustiça seria ainda mais prejudicial aos estudantes que sua aceitação tácita e costumeira por todos parece indicar uma perda de confiança global na capacidade de regulação das instituiçôes, que podem mesmo ser acusadas de buscar atingir, sob pretexto de direito, objetivos inconfessáveis. Trata-se bem, em todos esses acontecimentos, das relaçôes entre esfera pública e esfera privada e os acontecimentos-chave relatados fazem que se passe progressivamente de uma teoria "local" a uma teoria cada vez mais "formal". A possibilidade de efetuar paralelos entre os segmentos do sistema educativo permite ao mesmo tempo levar em conta e ultrapassar a "ciência dos atores". Pois, se existe, em direito, um continuum entre a experiência desses atores e a teorização que o pesquisador dela tenta fazer, somente a inscrição nas redes de conceitos, e mesmo nos paradigmas externos às situações e forjados por ocasião de outras pesquisas, feitas por ele ou por outros, permite produzir um saber "científico".

Apesar do seu grande interesse, essas metodologias não seriam suficientes para um trabalho sobre a pesquisa das competências. Elas devem, pelo menos, fundamentar-se em métodos de abordagens quantitativas sem as quais a pesquisa perde muito do seu valor. Aliás, parece que a oposição entre o quantitativo e o qualitativo tem, hoje em dia, um caráter bastante artificial. Com efeito, é necessário qualificar, mesmo implicitamente, o que se quer contar e quantificar, ainda que seja para uma avaliação em termos de proporçóes, nos fatos ou nas representaçóes cuja significação se quer compreender. Fiz, nas minhas pesquisas, uma utilização primeiro "passiva" dos dados quantitativos, considerando-os um campo de interesse sem o qual os elementos resultantes das entrevistas simplesmente não teriam sentido. Por exemplo, como se poderia compreender o que dizem os estudantes de liceu em matéria de legitimidade da ação política sem se lembrar das características dos comportamentos deles em matéria de inscrição nas listas eleitorais ou em matéria de participação nas diferentes eleições? Tais indicadores dão acesso a comportamentos gerais que, gravados durante um período suficiente, deixam ver 
pela análise das enquetes o que, nas palavras dos jovens, releva de circunstâncias particulares ou de comportamentos em longo prazo. Mas tentei também, em seguida, incluir nas próprias enquetes questionários comportando variáveis sociológicas clássicas suscetíveis de tirar do contexto o que as entrevistas, feitas ao acaso dos encontros e da abertura de espírito dos interlocutores, poderiam ter de demasiado singular. Dessa forma tentei dar maior alcance às minhas análises, submetendo às crianças cenários construídos com base em perguntas cujas entrevistas mostravam que tinham sentido para elas. ${ }^{8}$ Passá-las sob forma de questionários em escolas de recrutamento social variado, levando em conta variáveis clássicas, pôs em evidência fenômenos que, sozinhas, as entrevistas não mostrariam. Assim se pôde ver que a admiração diferencial das crianças pelos professores não provinha somente de um "feito professor" ou do temperamento de alunos particulares, mas se tratava também da maneira como as escolas públicas e as escolas privadas consideram a contribuição específica desses professores à carreira escolar das crianças.

Mas o recurso a técnicas quantitativas não tem, sem dúvida, como primeira e única finalidade reintroduzir, nas análises que se fundamentam em categorias sensivelmente diferentes das que prevalecem na sociologia "para adultos", consideraçôes que permitem ligar o mundo da experiência escolar ao mundo da sociedade global. Ele visa, sem dúvida, fundamentalmente a testar a existência de rotinas, como "atividades sociais cotidianas" (Giddens, 1987) por meio das quais as crianças e os jovens, como todos os atores sociais, estruturam o social a partir de recursos, eles mesmos depositados no "espaço-tempo" da experiência de umas e outros. Tratava-se, com efeito, de mostrar que nas interações em meio escolar há mais que a constituição de uma "profissão" ou de "perspectivas" que permitem fazer face a um problema dado. Ora, se a evocação de acontecimentos-chave ou de situações ressentidas como injustas coloca à mostra princípios subjacentes às expectativas dos entrevistados, ela não permite situar a importância de uns e de outras em circunstâncias mais comuns que aquelas que são relatadas com suficiente generalidade. $\mathrm{O}$ objetivo dos questionários é então o de abstrair as categorias evocadas no momento desses "negócios" (acontecimentos) e de transferi-las em situaçôes diferentes a fim de ver se elas exprimem somente ideais reavivados pelo caráter escandaloso de tal ou tal acontecimento ou os elementos matriciais de uma "gramática" bem mais comum. Os cenários colocam em cena pessoas e situaçóes depuradas nas quais cada um pode se reco- 
nhecer e a respeito das quais se pode supor que tal acontecimento exprimirá as competências gerais do ator social. A forma do questionário, se suas perguntas incidem sobre o universo de significaçôes daqueles a quem é destinada, pode então ter o poder de obrigá-los a escolher entre os princípios em função dos quais orientam suas ações.

No questionário destinado aos alunos, tomei assim a firme decisão de investigar se conceitos compartilhados dos "graus de grandeza" legítimos lhes permitiam respeitar o mundo escolar, no que concerne a eles, ligando entre si situações diferentes. Há ou não há um laço entre o modo de designar e de tratar aqueles de quem se diz que estão enamorados e o modo de resolver os conflitos no recreio? Parece que nesses casos (e em outros), trata-se de uma verdadeira construção sobre uma concepção comum, o de grau de grandeza aparente, seja a de "colecionador" de namorados ou a da habilidade em levar a melhor sobre o outro numa competição regulada. Considerando-se somente o caso das brigas, as respostas às questôes relativas ao direito de bater em alguém menor ou de se encarniçar contra aquele cuja derrota é bastante manifesta testemunham claramente o fato de que as brigas as mais violentas são sempre mediadas por um sentimento dividido entre o justo e o injusto. Nesse caso em que as entrevistas, sozinhas, fariam acreditar na existência de dois tipos de princípios distintos (a sala de aula e o pátio de recreio) adotados pelas crianças, os questionários permitem apreciar o seu grau de pertinência. Eles mostram, por exemplo, progressões bastante regulares na partilha das convicçóes, do $\mathrm{CP}^{9}$ ao $\mathrm{CM} 2$, a respeito de situaçóes que supõem uma adaptação das crianças às exigências cada vez maiores do sistema escolar, mas, em compensação, uma presença absoluta e nunca contestada de princípios que devem reger, desde o começo da escola primária, as interações no pátio de recreio. Ao passo que as entrevistas colocam relativamente entre parênteses as variáveis clássicas, para "dar sua chance" às características oriundas da própria experiência dos alunos, os questionários reintroduzem-nas e permitem precisamente desbloquear, por confrontação, o que pode relevar de uma sociologia da infância. A respeito dessas mesmas perguntas, vê-se aparecer, na margem da construção infantil, o peso das determinaçóes mais clássicas, como a origem socioprofissional ou o sexo: a briga continua sendo uma modalidade de confrontação mais aceitável para os meninos que para as meninas, para as crianças da escola pública que para as da escola privada, para as de meio popular que para as das classes superiores. 
$\mathrm{Na}$ realidade, uma dialética anima a utilização dessas duas metodologias. Se as entrevistas fazem sobressair o excepcional que informa sobre a norma, os questionários definem a pertinência desta última em situações cujas entrevistas permitiram também estabelecer uma espécie de cartografia. Elas autorizam igualmente uma sorte de classificação dos entrevistados, pois se torna possível, a posteriori, saber se o que foi dito por um ou outro aluno faz dele um porta-voz típico e autorizado de todos em cujo nome ele fala ou, pelo contrário, um caso extremo na experiência dos alunos considerados. O desejo de associar as diferentes abordagens do assunto, de modo evidentemente bastante intuitivo e incompleto, revela sem dúvida uma convicção íntima segundo a qual os universos sociais das crianças e dos jovens, no caso presente a maneira de eles se situarem com relação à organização social urbana, não são nem idênticos aos universos dos adultos, nem totalmente heterogêneos. As crianças ora são mais próximas, ora mais afastadas das normas dos adultos e, em cada um desses dois casos, a lógica que lhes é própria marca a da instituição ou se acha marcada por ela. Razão pela qual não são nem cidadãs, nem crianças-selvagens, mas vivem antes numa espécie de limbo, realidade cuja invenção pela igreja católica mostra bem a dificuldade que se tem a recusar a humanidade das crianças nas quais a instituição não reconhece ainda sua própria imagem.

\section{Na pista dos saberes}

A prática da entrevista semidirigida parece perfeitamente judiciosa para fazer aparecer as categorias que subtendem a relação dos alunos com os saberes. Para os estudantes de liceu, dissertadores, por exemplo (Rayou, 2002), o recurso a um "direito de reserva" parece servir de base a uma experiência bem diferente da que viveram seus professores, quando eles mesmos eram estudantes e reivindicavam a possibilidade de exprimir publicamente suas idéias em nome de um "tudo é político". Esses mesmos professores puderam igualmente criticar o dever de reserva que o estatuto deles lhes impóe e contestar uma laicidade medrosa que inspiraria o seu princípio. Do mesmo modo, a idéia de que uma espécie de reparação social se impõe àquele que, por sua excelência numa disciplina que o expõe, corre o risco de não mais ser visto como um jovem integrado na massa de seus colegas. Uma tal categoria influencia, é claro, a relação com o saber no sentido em que ela lhe fixa limites a não ultrapassar 
ou compensações a serem dadas no caso em que o "bobo"10 se manifeste sob um "ar inteligente", ${ }^{11}$ isto é, "sabichão". As entrevistas permitem igualmente dar sentido a dados fatuais recolhidos por um questionário. Como compreender, por exemplo, que 55\% dos alunos interrogados declaram preferir, quando eles preparam uma dissertação, contar somente consigo mesmos ao passo que, em contrapartida, afirmam a necessidade da solidariedade ou dizem trabalhar em equipe em outras matérias? Só a escuta da maneira como põem em relação suas concepções da "insubstituibilidade" das pessoas e a da expressividade da escrita em filosofia (com relação a outras disciplinas que julgam mais objetivas) pode ajudar a eliminar esse paradoxo. Do mesmo modo ainda, não se pode interpretar os resultados relativamente decepcionantes dos estudantes chamados "sócio-alunos" (Alava, 1999) nos exames se não se sabe, por eles mesmos, que os grupos que constituem servem mais a tranqüilizá-los e a agir sobre o curriculum prescrito que a ajudá-los a melhor se apropriarem dos saberes.

Mesmo se eles se interessam por um saber particular, essas entrevistas "clássicas" nos deixam ainda na soleira das atividades cognitivas. Pois os entrevistados, mesmo confiantes, não evocam espontaneamente o progresso de seus aprendizados. Segundo Lahire \& Johsua (1999), se somos convidados a contar como aprendemos a dirigir, falaremos mais facilmente da atitude mais ou menos inibidora do monitor do que do modo de como colocamos o pé no pedal. Os estudantes de liceu também falam de imediato da tensão que neles geram o último assunto de dissertação, da atmosfera na sala de aula quando o professor entrega as notas, muito menos da maneira como fazem o rascunho ou como procuram as referências pertinentes. É preciso, pois, sem dúvida, que nessa matéria as entrevistas sejam mais dirigidas, no sentido de impor, como fio condutor, a narração de etapas permitindo retomar o processo de aprendizado, pois o exercício feito e a nota obtida são apenas o resultado desse processo. Obriguei, pois, os alunos entrevistados a reviverem os diferentes momentos do "objeto" dissertação, desde a distribuição dos assuntos até a utilização do exame corrigido, com o fim de mostrar o que o forma nas pressões do tempo e do espaço sociais. Mas o objeto dissertação pode ele mesmo ser apreendido como o suporte de todo um trabalho de categorização que é possível fazer reaparecer. O que é verdade sobre o cinto de segurança deve ser também sobre um dever de filosofia. Com efeito, o primeiro pode ser visto como um objeto ao qual foi "delegado" um certo número de preocupações humanas às vezes contraditóri- 
as (Latour, 1988): trata-se de fazer do chofer um ser moral contra a sua vontade, minimizando, para ele mesmo e para outrem, o perigo que representa sua alta velocidade. Mas ao mesmo tempo o dispositivo deve garantir uma forma de liberdade da qual o ocidental amarrado a esse tipo de transporte faz questão. A regulação do cinto de segurança faz-se, pois, graças a uma "negociação" pela qual a possibilidade de obrigação máxima em caso de acidente possa compor com uma latitude ordinária de movimento num espaço considerado privado. A prova de filosofia pode ser considerada e analisada em si mesmo como meio de uma transação entre expectativas diferentes e às vezes contraditórias em si mesmas por parte de seus autores e de seus corretores. Ele tenta manter juntos saberes, boa vontade, prudência, rigor, compaixão etc. que o tornam dificilmente legível numa única lógica. Minha proposta de decodificação apóia-se em dois eixos que vêem o discurso do aluno se estruturar em parte na "horizontalidade" de sua análise e em parte, muitas vezes a maior, na "verticalidade" de referências que ele crê obrigatórias, e inspira-se em uma metodologia da pesquisa que insere os objetos na construção das situaçóes sociais. No caso preciso das disciplinas escolares, uma tal maneira de abordar o assunto pode ter o mérito de ir mais longe na alquimia que preside a construção de tal ou tal saber particular.

O objeto, não confiando jamais seus segredos por si mesmo, um trabalho de "reaquecimento", sobretudo por meio de paralelos constantes com o conteúdo das entrevistas, impóe-se no intuito de tentar recriar o processo do qual esse objeto é o resultado. Mas, em contrapartida, o interesse de um produto acabado é que ele se torna transferível e pode ser analisado em condiçōes de objetivação diferentes, outras que a do seu autor. Com efeito, é possível atribuir o estatuto de expertos a outras pessoas, alunos ou professores que "sabem" o que é uma dissertação e trocam olhares sobre um exame que poderiam ter tido que redigir ou corrigir. Tive assim a idéia de formar "júris" inspirando-me no método de enquete de Luc Boltanski (1990), a respeito de cartas de denúncia recebidas pelo jornal Le Monde e confiadas a leitores supostos de classificá-las em função da sua "normalidade". Um critério importante desta última se manifesta na idéia de tornar menos singular o caso evocado pelos queixosos e permite aceder às regras de composição desse exercício banal, mas que obedece a uma norma estabelecida. Do mesmo modo, os olhares trocados sobre provas de filosofia permitem distinguir o que releva da expertise pura e simples, estudantes de liceu e professores estando, impressionantemente, de acordo quanto à 
hierarquia a estabelecer entre eles no que importa de "pontos de justiça" concedidos pelos corretores ou por alunos da mesma classe do colega cuja produção eles avaliam. $\mathrm{Na}$ distância entre a apreciação puramente técnica e a avaliação final abre-se o espaço para uma negociação que torna então legítimo o exame de todos os seus meandros.

No fundo, é sem dúvida nesse tipo de desvio entre o que é prescrito e o que é real que se pode engajar uma sociologia curricular. Mas ela deve, por esta razão, estar bastante atenta ao que dela se espera verdadeiramente e que, para cada saber particular, não se resume a posturas gerais diante da cultura escolar. Assim é que participei de um trabalho interdisciplinar, cuja metodologia mereceria sem dúvida ser explorada de novo, que confrontava uma equipe de diversos especialistas das ciências da educação (Rayou, 1999b) com uma seqüência filmada de um curso de matemática em situação aberta. $\mathrm{O}$ ponto de vista sociológico sobre essa sequiência parece fundado, em particular, quando ele mostra o trabalho do professor para conciliar, pelos seus movimentos, sua gestualidade, suas palavras, imperativos indispensáveis de justiça e de proximidade destinados, por exemplo, a considerar cada aluno o responsável pela tarefa a executar, mas manifestando a alguns uma solicitude sem a qual abandonariam o exercício. Se parece bastante claro que a preocupação principal do sociólogo são as normas que mantêm as sociedades (Elster, 1989), é preciso ainda saber onde podem passar as linhas de ruptura. $\mathrm{O}$ que parece também válido para as atividades de aquisição de conhecimentos na sala de aula. Um professor que recusa sua ajuda a um aluno poderá parecer desdenhoso, se se ignora que ele se acha num momento da aula no qual a regra é precisamente a de deixar o aluno mobilizar sozinho recursos cognitivos. Pelo contrário, ele será visto como laxista quando suaviza suas ordens, se não se sabe que seu intuito não é o de criar uma situaçãoproblema na qual os alunos devem inventar um novo saber, mas uma situação aberta para a qual se trata de utilizar, numa nova configuração, noções já familiares. É verossímil que a análise sociológica da relação com o saber teria a ganhar com o estudo de seqüências de aprendizado cujos ganhos ou perdas cognitivos e não-cognitivos poderiam ser explicitados a partir de vários campos de pesquisa em educação. As próprias ciências da educação afirmariam assim uma vocação de pluralidade indo além da simples justaposição das disciplinas que a constituem ou da afirmação de uma complexidade constitutiva de cada uma delas que somente leva muitas vezes, na realidade, a diluir seus objetivos e suas análises. 
As tentativas metodológicas anteriormente apresentadas permanecem bastante próximas da bricolagem. Elas acompanham o nascimento de uma sociologia das crianças e dos jovens que teve e tem, na França, particularmente, dificuldade em se desenvolver, pois crianças e jovens durante muito tempo foram considerados adultos em formação e estudados por meio de categorias forjadas para os adultos. Não se trata, é claro, assim fazendo, de romper com as regras metodológicas clássicas, mas de permanecer muito atento ao fato de que as categorias de construção do social às quais elas nos dão acesso não assimilam valores, normas e regras elaboradas para fazer face a situações que não são precisamente as que conhecem os mais jovens, sobretudo na escola. Não se poderia, aliás, propor que, de modo paradoxal, longe de diminuir suas exigências, as pesquisas sobre a infância e a juventude ajudem a sociologia "normal" de hoje a melhor discernir os comportamentos de atores cada vez menos redutíveis ao desempenho de papéis estritamente determinados?

\section{Recebido em novembro de 2004 e aprovado em março de 2005.}

\section{Notas}

1. Começa-se o liceu em classe de Segunda, normalmente aos 15 anos, depois passa-se à Primeira e, em seguida, à Terminal, no fim da qual se passa a um exame final.

2. A dissertação é uma especificidade francesa. Ela se distingue dos outros exercícios e consiste em uma devolução do problema ao aluno, que deve explicitá-lo e lhe dar uma resposta pessoal argumentada.

3. $71,2 \%$ dos candidatos não obtêm a média na prova escrita do exame final do secundário (nota de informação da Direção da Avaliação e da Prospectiva, 95-11, fevereiro de 1995).

4. Minha pesquisa referiu-se a 49 alunos a partir da Segunda e interrogados regularmente durante todo o período de freqüentação do liceu.

5. Padre na origem de numerosas ações de caráter humanitário.

6. Num jornal que editavam, os estudantes tinham zombado de professores e de membros da administração.

7. Espécie de carnaval organizado pelos alunos do último ano do secundário (Terminal) 100 dias antes dos exames finais.

8. Interessando-me, por exemplo, no sentido de justiça que o jogo de bolinhas-de-gude implica ou na legitimidade de ter vários namorados ou namoradas.

9. O Curso Preparatório constitui o primeiro ano do ensino primário, o Curso Médio, o segundo ano, constitui seu último ano. Uma vez terminado, as crianças, que têm normalmente 11 anos, entram no colégio, primeira etapa do segundo grau. 
10. Os alunos, de colégio, sobretudo, assim chamam e ridicularizam os colegas que os adultos distinguiram pelos bons resultados obtidos.

11. Aquele que, aos olhos dos colegas, desenvolveu por demais suas capacidades intelectuais.

\section{Referências bibliográficas}

ALAVA, S. Les profils d'autodirection et les pratiques informelles d'études des étudiants en $1^{\text {ère }}$ année d'université. Hétérogénéité et réussite dans le premier cycle universitaire, CREFI, Rapport au CNCRE, 1999.

BASZANGER, I.; DODIER, N. Totalisation et altérité dans l'enquête ethnographique. Revue Française de Sociologie, n. 38, 1997.

BOLTANSKI, L.; THÉVENOT, L. Les économies de la grandeur. Paris: PUF, 1987.

BOLTANSKI, L. L'amour et la justice comme compétences. Trois essais de sociologie de l'action. Paris: A.-M. Métailié, 1990.

CALLON, M. La domestication des coquilles St. Jacques et des marins pêcheurs dans la baie de St. Brieuc. L'année sociologique. Paris: PUF, 1986.

CORCUFF, P. Les nouvelles sociologies. Constructions de la réalité sociale. Paris: Nathan Université, 1995.

CREFI; CREN; IREDU. Hétérogénéité et réussite dans le premier cycle universitaire. Rapport au CNCRE, 1999.

DEMAZIÈRE, D.; DUBAR, C. Analyser les entretiens biographiques. L'exemple des récits d'insertion. Paris: Nathan, 1997. (Essais et Recherches)

DODIER, N. Agir dans plusieurs mondes. Critique, 47 (529-530), p. 427-458, juin-juil. 1991.

DUBET, F. Le déclin de l'institution. Paris: Seuil, 2002.

DURKHEIM, É. Éducation et sociologie. Paris: PUF, 1966. (1 1 ère édition: 1922)

ELSTER, J. The cement of society. A study of social order. Cambridge: Cambridge University Press, 1989.

GIDDENS, A. La constitution de la société. Paris: PUF, 1987. 
HIRSCHMAN, A.O. Face au déclin des entreprises et des institutions. Paris: Les Éditions Ouvrières, 1972.

KUNDERA, M. La plaisanterie. Paris: Gallimard, 1985.

LAHIRE, B.; JOHSUA, S. Pour une didactique sociologique. Éducation et Sociétés, n. 4, 1999.

LATOUR, B. Les microbes. Guerre et paix, suivi de Irréductions. Paris: A.-M. Métailié, 1984.

LATOUR, B. La ceinture de sécurité. In: SChWARTZ, M.; JANSMA, R. (Ed.). The technological culture. Johannesburg: De Ball Publishers, 1988.

MONTANDON, C.; OSIECK, F. L'éducation du point de vue des enfants. Paris: L'Harmattan, 1997.

PIAGET, J. Le jugement moral chez l'enfant. Paris: PUF, 1932.

POLLARD, A. Life in school. The sociology of pupil culture. Ed. M. Hammersley and P. Woods. London: Open University Press, 1984.

POLLARD, A. Studying children's perspectives. A collaborative approach. In: Wallford, G. Doing sociology of education. New York, Philadephia, London: The Falmer Press, 1987.

RAYOU, P. La cité des lycéens. Paris: L'Harmattan/Débats/Jeunesses, 1998.

RAYOU, P. La grande école. Paris: PUF, 1999a.

RAYOU, P. Construire une cité savante. In: Analyse plurielle d'une séquence d'enseignement-apprentissage. Cahiers du CREN, CRDP des Pays de la Loire, 1999b.

RAYOU, P. Un vilain petit canard. In: Derouet, J.-L. (Dir.). L'école dans plusieurs mondes. Paris-Bruxelles: INRP-De Boeck, 2000.

RAYOU, P. La “dissert de philo". Sociologie d'une épreuve scolaire. Rennes: PUR, 2002.

STRAUSS, A. La méthode comparative continue en analyse qualitative. In: Baszanger, I.(Dir.). La trame de la négociation.. Paris: L'Harmattan, 1992. (Logiques Sociales)

WILCOX, K. Ethnography as a methodology and its application to the study of schooling: a review. In: SPINDLER, G. Doing the ethnography of schooling. New York: CBS College Publishing, 1982. 